\title{
ANALISIS RANTAI PEMASARAN KAYU SERTIFIKASI FSC DI KABUPATEN KULON PROGO
}

\author{
Wiyono $^{1}$, Silvi Nur Oktalina ${ }^{2}$, Rochmat Hidayat ${ }^{3}$ \\ ${ }^{1,2,3}$ Program Studi Pengelolaan Hutan/Departemen Teknologi Hayati dan Veteriner/Sekolah \\ Vokasi, Universitas Gadjah Mada, Indonesia \\ Email: ${ }^{1}$ wiyono.putro@gmail.com; ${ }^{2}$ silvi.nuroktalina@ugm.ac.id; ${ }^{3}$ rochmad.hidayat@ugm.ac.id
}

\begin{abstract}
Forest certification is a market-based policy instrument aimed to ensuring that any traded timber is legal and derived from sustainably managed forests. Forest certification is not only applied to large scale forest management but also small scale such as community forest. This study aims: (1) to know the pattern of marketing chain of certified timber; (2) to know the actors involved in the marketing of certified timber; (3) to know the marketing constrains of certified timber faced by farmers. This research was conducted at Wana Lestari Menoreh Cooperative (KWLM) in Kulon Progo Regency. KWLM is a community forest cooperative that has successfully obtained a certificate of sustainable forest management with Forest Stewardship Council (FSC) standard since 2011. Data collection is done by: (1) in-depth interviews to actors involved in marketing of certified wood; (2) observation of each stage of certified timber marketing chain; (3) study documents related to marketing chain of certified timber. Data then analyzed descriptive method. The results show that: (1) the pattern of marketing chain of certified wood is simpler than non certified timber; (2) The actors involved in the marketing chain of certified timber are farmers, harvester, cooperation, PT SOBI, wood processing industry; (3) The major constraint faced by farmers in marketing of certified timber is a payment that do not made in cash as done by non-certified timber trader.
\end{abstract}

Keywords: marketing chain, timber, community forest, certification, FSC

\section{PENDAHULUAN}

Sertifikasi hutan merupakan instrumen kebijakan hutan berbasis pasar yang didesain untuk meningkatkan pengelolaan hutan secara lestari dengan mendorong pembeli untuk dapat mengidentifikasi bahwa kayu yang dibeli berasal dari hutan yang dikelola secara lestari (Maryudi, 2006; 2009). Sertifikasi hutan menggunakan stick and carrot approach, yaitu mendorong pengelolaan hutan lestari melalui kampanye boikot produk kayu (stick) dari hutan yang tidak dikelola secara lestari, dan juga menawarkan insentif (carrots), yaitu akses pasar yang lebih baik dan harga premium kepada pengelola hutan yang mampu mengelola hutan secara lestari (Cashore et al., 2004 dalam Maryudi, 2005a).

Pada awalnya program sertifikasi hanya diterapkan pada pengusahaan hutan skala besar. Ada kekhawatiran bahwa program sertifikasi tidak cocok diterapkan pada pengusahaan hutan skala kecil, seperti hutan rakyat (Cashore et al., 2004 dalam Maryudi, 2005b). Forest Stewardship Council (FSC), sebagai sebuah lembaga standarisasi hutan internasional telah menjawab kendala penerapan sertifikasi hutan rakyat tersebut dengan menerbitkan standar FSC-Group Certification (Harada, et al, 2012; 2014; Maryudi, 2005a; 2005b; Hinrichs, et al., 2008). Dengan menggunakan standar tersebut sertifikasi hutan rakyat dapat dilakukan secara berkelompok. Beberapa petani hutan rakyat dapat bergabung membentuk satu unit manajemen atau lembaga pengelola hutan rakyat bersama. Lembaga pengelola hutan rakyat ini memiliki peran strategis dalam sertifikasi hutan rakyat, yaitu untuk memenuhi persyaratan standar sertifikasi yang tidak dapat dilakukan oleh petani secara perorangan (Harada, et al, 2012; 2014; Hinrichs, et al, 2008). Lembaga pengelola hutan rakyat juga harus bersifat legal dan formal yang dilengkapi dengan aturan, struktur organisasi dan kepengurusan yang terdokumentasi dengan jelas. Pemimpin lembaga pengelola hutan rakyat juga harus mampu berperan sebagai leader, manager 
sekaligus entrepreneur dalam menjalankan program sertifikasi hutan rakyat (Wiyono dan Nuroktalina, 2013).

Di Indonesia tidak banyak kelompok tani atau koperasi hutan rakyat yang berhasil memperoleh sertifikat FSC. Ada beberapa kendala yang dihadapi untuk penerapan sertifikasi hutan rakyat, yaitu: (1) Minimnya pengetahuan petani hutan terhadap program sertifikasi hutan; (2) Biaya sertifikasi yang terlalu mahal dan mungkin tidak viable untuk pengelolaan hutan rakyat; (3) Manajemen dan kelembagaan pengelolaan hutan rakyat yang masih lemah (Maryudi, 2005b).

Koperasi Wana Lestari Menoreh (KWLM) di Kabupaten Kulon Progo adalah salah satu koperasi pengelola hutan rakyat yang telah berhasil memperoleh sertifikat FSC sejak tahun 2011. Setelah 6 tahun sejak KWLM memperoleh sertifikat FSC, tentunya telah banyak pengalaman berharga yang menarik untuk diteliti terkait pemasaran kayu sertifikasi. Penelitian ini bertujuan untuk: (1) mengetahui pola rantai pemasaran kayu sertifikasi; (2) mengetahui aktor-aktor yang terlibat dalam pemasaran kayu sertifikasi; (3) mengetahui kendala pemasaran kayu sertifikasi yang dihadapi oleh petani.

\section{BAHAN DAN METODE PENELITIAN}

Penelitian ini dilaksanakan di Koperasi Wana Lestari Menoreh (KWLM) di Kabupaten Kulon Progo. Penelitian dilaksanakan pada bulan Maret sampai dengan Oktober 2017. Pengambilan data dilakukan dengan cara: (1) wawancara mendalam dengan para aktor yang terlibat dalam pemasaran kayu sertifikasi; (2) observasi terhadap setiap tahapan rantai pemasaran kayu sertifikasi; (3) telaah dokumen yang terkait rantai pemasaran kayu sertifikasi. Data hasil penelitian kemudian dianalisis secara deskriptif.

\section{HASIL DAN PEMBAHASAN}

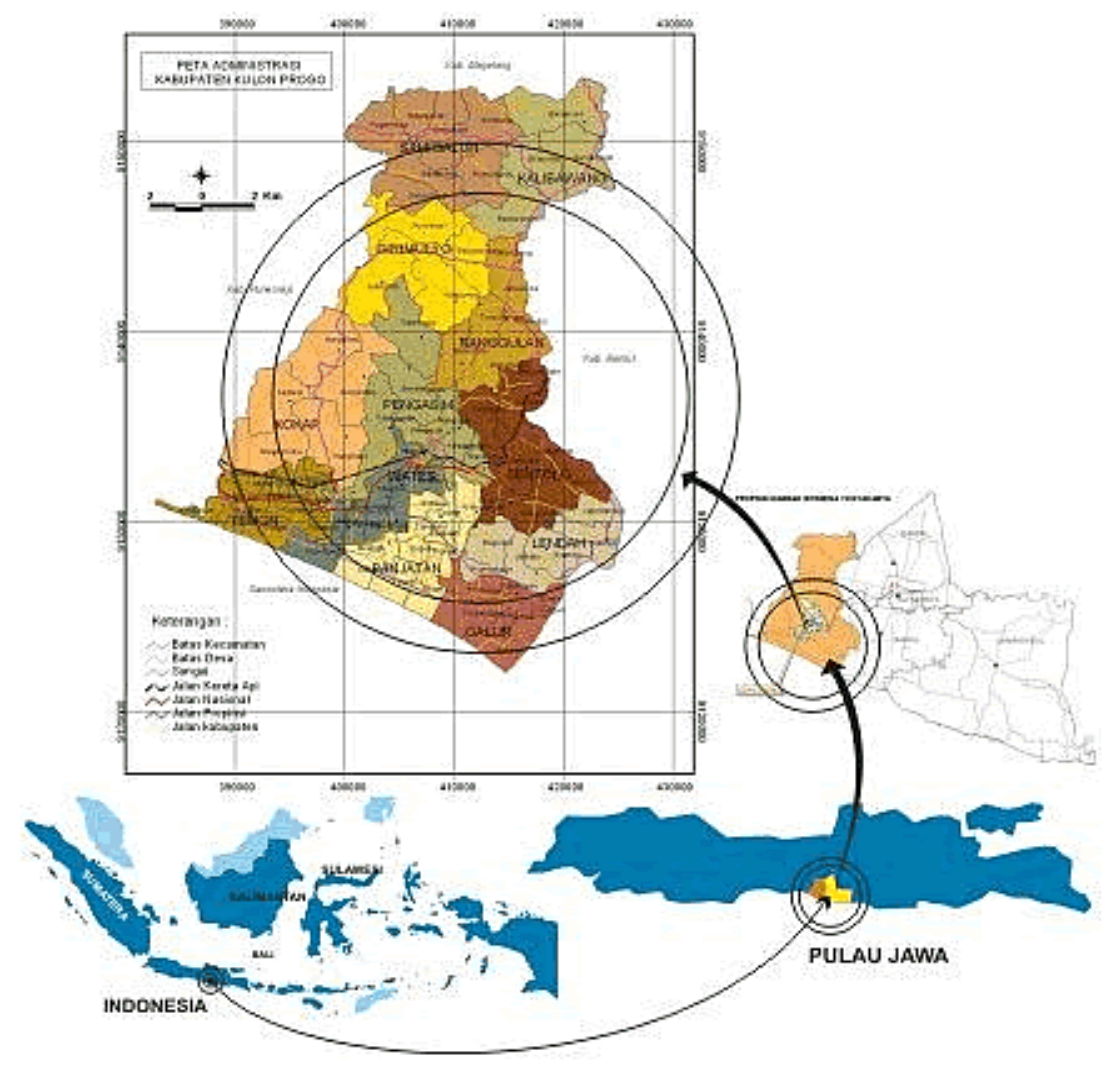

Gambar 1. Lokasi penelitian di Kabupaten Kulon Progo

Kabupaten Kulon Progo memiliki luas wilayah 586,28 km², terdiri dari 12 kecamatan dan 88 desa dengan jumlah penduduk 388.869 jiwa (Pemerintah Daerah Kabupaten Kulon Progo, 2015). 
Sebagian besar penduduk Kabupaten Kulon Progo adalah petani. Lahan pertanian berupa sawah sebagian besar berada di bagian selatan dan hutan rakyat berada di kawasan Pegunungan Menoreh di bagian utara. Luasan hutan rakyat di Kabupaten Kulon Progo terus berkembang dari 18.731,97 ha pada tahun 2010 menjadi 20.392,30 pada tahun 2014 (Dinas Pertanian dan Kehutanan Kabupaten Kulon Progo, 2015). Rata-rata luas kepemilihan lahan hutan rakyat di Kabupaten Kulon Progo adalah 0,45 ha per petani. Jenis pohon yang banyak ditanam oleh para petani hutan rakyat di Kabupaten Kulon Progo adalah jati, sonokeling, mahoni, akasia, dan sengon. Pada tahun 2011 produksi kayu dari hutan rakyat di Kabupaten Kulon Progo sebanyak 47.320,75 $\mathrm{m}^{3}$ yang didominasi oleh jenis kayu jati, yaitu sebanyak 30.734,02 $\mathrm{m}^{3}$ atau sekitar 64,95\% (BPS Kabupaten Kulon Progo, 2012).

Tabel 1. Produksi kayu dari hutan rakyat di Kabupaten Kulon Progo Tahun 2011

\begin{tabular}{c|lcc}
\hline No. & Jenis Kayu & Volume $\left(\boldsymbol{m}^{3}\right)$ & Persen (\%) \\
\hline 1. & Jati & $30.734,02$ & 64,95 \\
2. & Sonokeling & $2.571,03$ & 5,43 \\
3. & Mahoni & $6.732,72$ & 14,23 \\
4. & Akasia & 481,48 & 1,02 \\
5. & Sengon & $5.359,59$ & 11,33 \\
6. & Rimba & $1.441,91$ & 3,05 \\
\hline & Jumlah & $\mathbf{4 7 . 3 2 0 , 7 5}$ & $\mathbf{1 0 0}$ \\
\hline
\end{tabular}

Sumber: BPS Kabupaten Kulon Progo, 2012

Koperasi Wana Lestari Menoreh (KWLM) adalah sebuah badan usaha berbadan hukum koperasi yang berdiri pada tanggal 2 Agustus 2008 dan berkedudukan di Kabupaten Kulon Progo. Pada awalnya KWLM didirikan oleh 20 orang anggota. Anggota KWLM adalah para petani hutan rakyat yang berdomisili di sekitar kawasan Pegunungan Menoreh. Tujuan pendirian KWLM adalah untuk: (1) meningkatkan mutu pengelolaan lahan hutan rakyat para anggota; (2) memfasilitasi akses pasar dan meningkatkan harga jual kayu dari hutan rakyat; (3) meningkatkan kesejahteraan anggota; (4) membina anggota agar mampu melakukan pengelolaan hutan rakyat secara lestari; (5) menjembatani saling tukar pengalaman dan wawasan dalam pengelolaan hutan rakyat para anggota; (6) mendapatkan sertifikat pengelolaan hutan lestari dengan standar FSC.

Pada tahun 2011 KWLM telah berhasil meraih sertifikat Forest Management and Chain of Custody sesuai standar FSC. Jumlah anggota KWLM terus berkembang dari 1.504 orang pada tahun 2011 menjadi 1.504 orang pada tahun 2017. Luas lahan hutan rakyat yang disertifikasi KWLM juga berkembang dari 220 ha pada tahun 2011 menjadi 800 ha pada tahun 2017. Jatah tebangan kayu sertifikasi KWLM meningkat dari $934 \mathrm{~m}^{3} /$ tahun pada tahun 2011 menjadi $2.300 \mathrm{~m}^{3} /$ tahun pada tahun 2017. Penjualan kayu sertifikasi KWLM juga meningkat dari $14,04 \mathrm{~m}^{3}$ dengan nilai penjualan $\mathrm{Rp}$ 54.203.800,- pada tahun 2011 menjadi $608,52 \mathrm{~m}^{3}$ dengan nilai penjualan $\mathrm{Rp} 1.324 .801 .953$,- pada tahun 2014.

\section{Rantai pemasaran kayu non-sertifikasi}

Hutan rakyat merupakan tanaman pohon-pohonan yang tumbuh atau sengaja ditanam di lahan milik rakyat, seperti pekarangan, tegalan dan hutan (wono). Para pemilik hutan rakyat menganggap pepohonan tersebut sebagai tabungan. Oleh karena itu, penebangan pohon hanya dilakukan ketika mereka membutuhkan uang dalam jumlah besar seperti untuk biaya sekolah anak, hajatan, membuat rumah dan membeli kendaraan atau untuk memenuhi kebutuhan mendadak seperti biaya pengobatan. Sistem penebangan pohon yang demikian dikenal dengan nama tebang butuh.

Secara konvensional pola penjualan kayu dari hutan rakyat di Kabupaten Kulon Progo dapat diklasifikasikan menjadi tiga, yaitu: (1) pola tebasan; (2) pola pilihan; (3) pola galondongan. Pola tebasan yaitu penjualan kayu dalam bentuk pohon berdiri yang dilakukan terhadap seluruh pohon 
yang berada dalam satu hamparan lahan dengan penentuan harga dilakukan untuk seluruh pohon (tebasan). Pola pilihan yaitu penjualan kayu dalam bentuk pohon berdiri yang dilakukan terhadap pohon-pohon terpilih dengan penentuan harga dilakukan untuk setiap pohon. Pola gelondongan yaitu penjualan kayu dalam bentuk gelondongan $(\log )$ yang sudah ditebang dan penentuan harga dilakukan untuk setiap potongan $\log$. Pada pola tebasan dan pola pilihan, biaya penebangan, penyaradan dan pengangkutan kayu menjadi tanggung jawab pembeli. Sementara itu, pada pola gelondongan, biaya penebangan dan penyaradan di tanggung oleh petani. Sebagian besar petani lebih memilih pola tebasan dan pola pilihan dibandingkan pola gelondongan, karena mereka tidak perlu mengeluarkan biaya tambahan untuk kegiatan penebangan dan penyaradan.

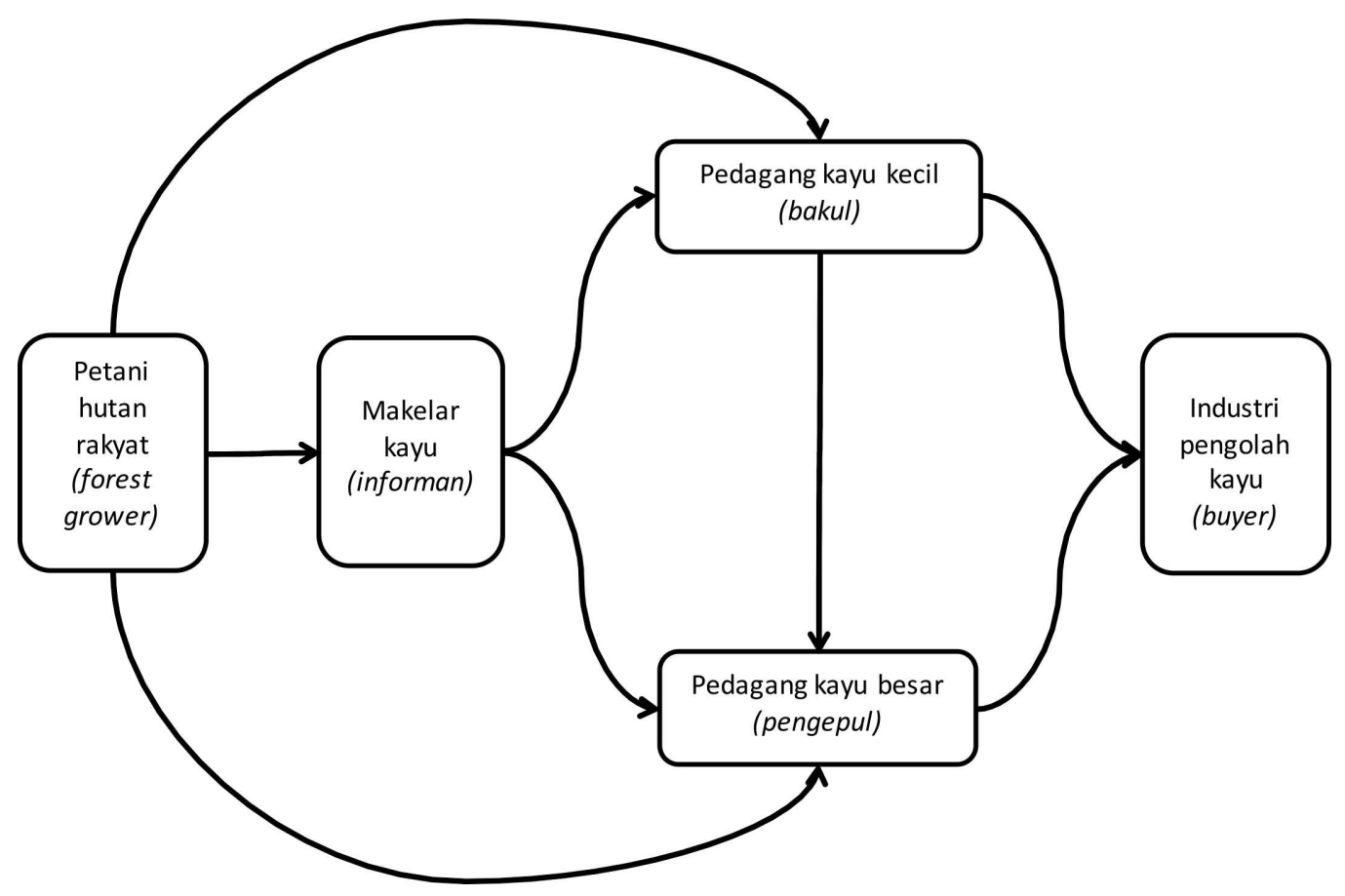

Gambar 2. Rantai pemasaran kayu non-sertifikasi

Secara umum rantai pemasaran kayu dari hutan rakyat di Kabupaten Kulon Progo melibatkan petani, makelar, bakul, pengepul dan industri pengolah kayu. Petani sebagai pemilik hutan rakyat berperan melakukan penanaman, pemeliharaan, perlindungan dan penjualan kayu. Makelar berperan mencari informasi penjualan kayu di tingkat petani dan memberikan informasi tersebut kepada para bakul atau pengepul. Bakul berperan membeli kayu dari para petani kemudian menjualnya kepada para pengepul atau langsung kepada industry pengolah kayu. Pengepul berperan membeli kayu dari para petani atau para bakul kemudian menjualnya kepada industry pengolah kayu. Sementara itu, industry pengolah kayu berperan membeli kayu dari para bakul dan pengepul kemudian mengolahnya menjadi produk olahan kayu, seperti kayu gergajian, kayu lapis, furniture, dan lain-lain.

Tabel 1. Aktor pemasaran kayu non-sertifikasi

\begin{tabular}{|c|c|c|}
\hline No. & Aktor & Peran \\
\hline 1. & $\begin{array}{l}\text { Petani hutan rakyat } \\
\text { (Forest grower) }\end{array}$ & $\begin{array}{l}\text { Melakukan penanaman, pemeliharaan dan perlindungan } \\
\text { pohon } \\
\text { - Melakukan penjualan kayu melalui makelar atau langsung } \\
\text { kepada bakul atau pengepul. }\end{array}$ \\
\hline
\end{tabular}




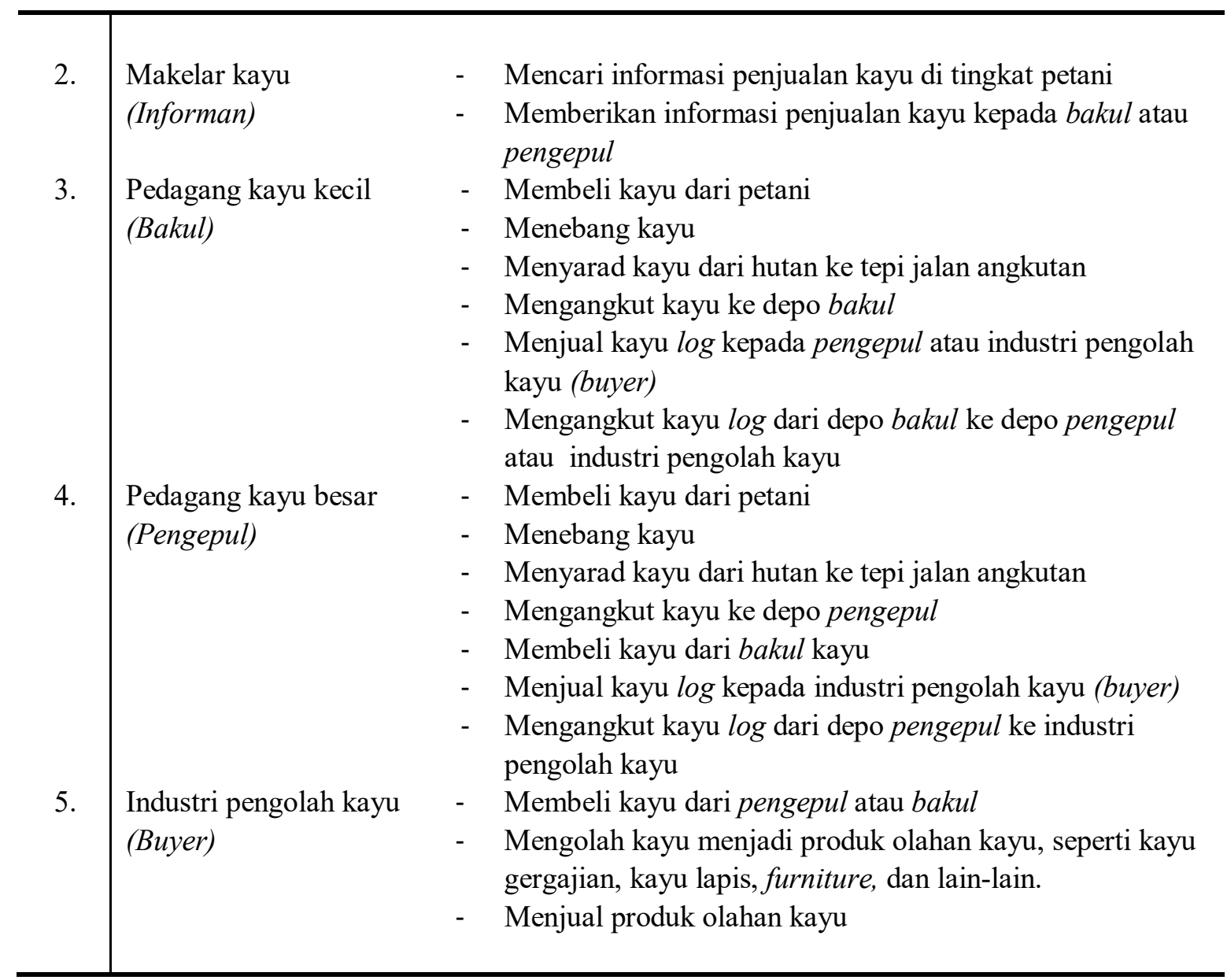

Sumber: Data primer.

Rantai pemasaran kayu secara konvensional tersebut memiliki beberapa kelebihan, yaitu: (1) Penjualan kayu dapat dilakukan setiap saat kepada para pedagang kayu; (2) Pembayaran pada umumnya dilakukan secara kontan, bahkan ada juga yang dilakukan sebelum kayu ditebang; (3) Petani tidak dibebani dengan biaya penebangan, penyaradan dan pengangkutan. Namun demikian, rantai pemasaran kayu dari hutan rakyat secara konvensional tersebut juga memiliki beberapa kelemahan, yaitu: (1) Kelestarian hutan tidak terjamin karena tidak ada sistem pengaturan hasil pemanenan kayu; (2) Penjualan kayu terbatas hanya kepada pedagang kayu lokal; (3) Posisi tawar petani dalam penentuan harga kayu lemah karena harga kayu lebih banyak ditentukan oleh para pedagang kayu; (4) Penentuan harga kayu tidak transparan karena dilakukan pada saat pohon berdiri di hutan, sementara penjualan kayu ke industri dilakukan dalam bentuk sortimen (log); (5) Asal-usul kayu sulit dilacak karena tidak menerapkan sistem lacak balak (chain of custody).

\section{Rantai pemasaran kayu sertifikasi}

Keberadaan KWLM bertujuan untuk memperbaiki rantai pemasaran kayu dari hutan rakyat. Beberapa strategi yang telah dilakukan oleh KWLM terkait pemasaran kayu sertifikasi adalah sebagai berikut: (1) Transparansi penentuan harga kayu sertifikasi; (2) Meningkatkan harga kayu sertifikasi; (3) Menerapkan system pengaturan pemanenan hasil hutan; (4) Menerapkan sistem lacak balak kayu (chain of custody); (5) Memperluas jaringan pemasaran kayu sertifikasi.

Upaya KWLM untuk melakukan transparansi dalam penentuan harga kayu sertifikasi dilakukan dengan cara membeli kayu dari petani dalam bentuk sortimen atau kayu log, bukan pohon berdiri. Dengan demikian, taksiran volume kayu yang dijual oleh petani menjadi lebih akurat. Upaya KWLM guna meningkatkan harga jual kayu sertifikasi dilakukan dengan cara mencari buyer yang bersedia membayar lebih untuk kayu sertifikasi. Buyer kayu sertifikasi pada umumnya adalah industri yang 
sudah memiliki sertifikat FSC, sehingga mereka bersedia membayar premium price lebih tinggi 20 $30 \%$ dibandingkan dengan harga kayu non-sertifikasi.

Upaya KWLM untuk menjamin kelestarian hutan rakyat diantaranya dilakukan dengan cara menerapkan sistem pengaturan pemanenan hasil hutan, seperti penetapan Jatah Tebang Tahunan (JTT) dan penetapan batas diamater pohon minimum yang boleh ditebang. Total volume penebangan kayu dalam satu tahun tidak boleh melebihi JTT. Penetapan JTT didasarkan pada hasil inventarisasi potensi tegakan/pohon dan rencana pengaturan pemanenan kayu. Pohon yang boleh ditebang adalah yang berdiamater di atas $30 \mathrm{~cm}$. Kebijakan ini diterapkan untuk mengendalikan terjadinya tebang butuh. Jika petani membutuhkan uang sementara pohon yang dimiliki diameternya kurang dari $30 \mathrm{~cm}$, maka petani tidak perlu melakukan penebangan pohon tetapi cukup dengan mengajukan pinjaman uang kepada KWLM dengan agunan pohon tersebut. Pohon yang diagunkan akan ditebang oleh KWLM ketika dimaternya sudah lebih dari $30 \mathrm{~cm}$.

KWLM berkomitmen untuk ikut mengendalikan penebangan kayu liar (illegal logging), salah satu upaya yang dilakukan adalah dengan menerapkan system lacak balak kayu (chain of custody). Setiap kayu yang ditebang dicatat asal-usulnya meliputi: nama pemilik, nomor persil lahan, lokasi tonggak, jenis pohon, jumlah potongan kayu (sortimen), volume kayu, nama penebang, nama sopir pengangkut dan jenis kendaraan pengangkut. Setiap kayu yang ditebang juga dilengkapi dengan dokumen angkutan dan legalitas kayu. Tujuannya adalah untuk menjamin bahwa setiap kayu yang diperdagangkan oleh KWLM adalah kayu legal dan asal usulnya jelas, yaitu berasal dari hutan rakyat yang dikelola secara lestari.

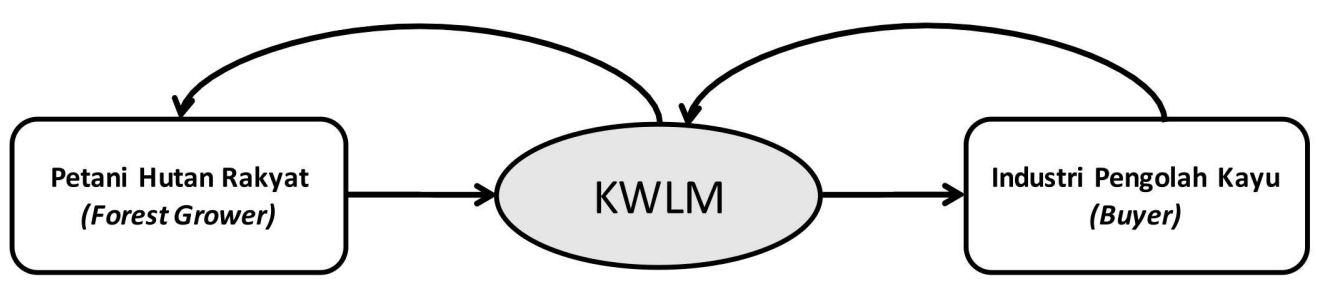

(i) Rantai pemasaran kayu sertifikasi tahun 2011 - 2016

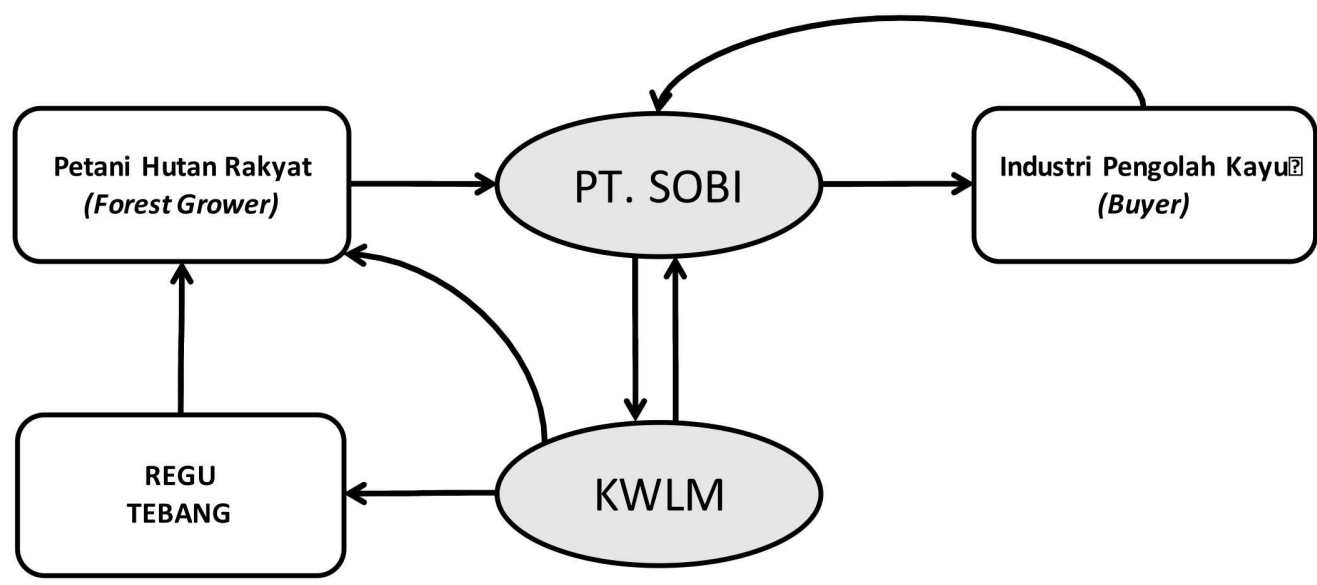

(ii) Rantai pemasaran kayu sertifikasi sejak tahun 2017

Gambar 3. Rantai pemasaran kayu sertifikasi di Kabupaten Kulon Progo

Perluasan jaringan pemasaran kayu sertifikasi yang dilakukan oleh KWLM adalah dengan cara promosi kayu sertifikasi melalui jalur tatap muka dengan buyer, website, jaringan FSC serta menjalin kerjasama dengan industri pemasaran dan pengolah kayu. Pada tahun 2011 - 2016 pemasaran kayu 
sertifikasi dilakukan secara mandiri oleh KWLM. Sementara itu sejak tahun 2017, KWLM menjalin kerjasama dengan PT SOBI untuk perluasan pasar kayu sertifikasi. Ada beberapa peran yang selama ini dilakukan oleh KWLM kemudian menjadi tanggung jawab PT SOBI, diantaranya yaitu: (1) Pengelolaan dan pembiayaan sertifikasi FSC; (2) melakukan pembelian dan pemasaran kayu sertifikasi; (3) Melakukan pemetaan lahan, inventarisasi potensi tegakan, dan penyusunan rencana pengaturan kelestarian hasil pemanenan kayu; (4) Menyiapkan kelengkapan dokumen administrasi penjualan dan legalitas kayu. Pembagian keuntungan antara KWLM dengan PT SOBI adalah 55\% untuk PT SOBI dan 45\% untuk KWLM. Sejak tahun 2017 KWLM juga menjalin kerjasama dengan regu tebang. Tugas regu tebang yaitu: (1) Melakukan penebangan pohon di lahan; (2) Melakukan penyaradan kayu dari lahan sampai di tepi jalan angkutan; (3) Mengangkut log dari tepi jalan angkutan ke Tempat Penimbunan Kayu Terdaftar (TPT).

Tabel 2. Peran para aktor pemasaran kayu sertifikasi

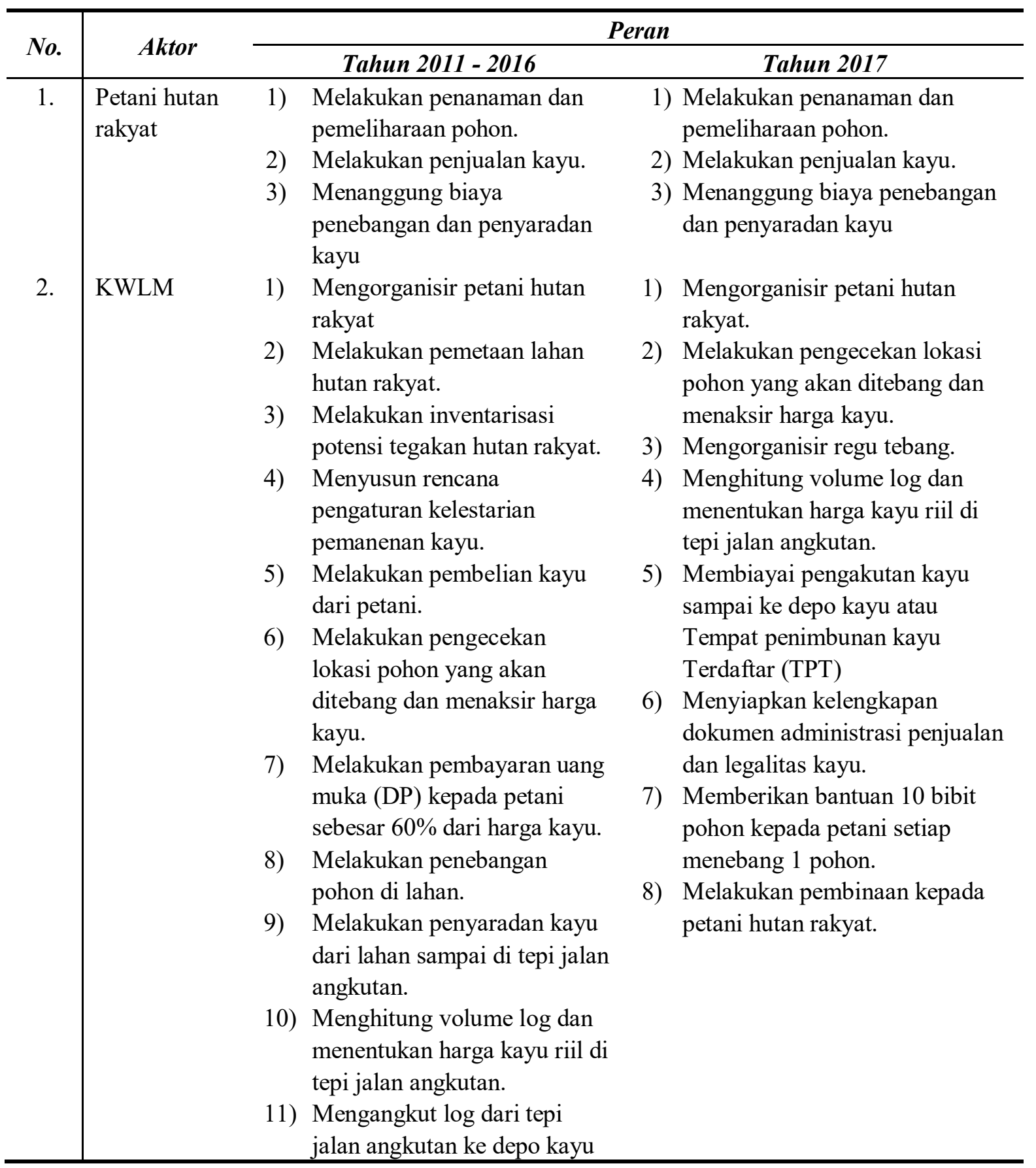




\begin{tabular}{|c|c|c|c|c|c|}
\hline & 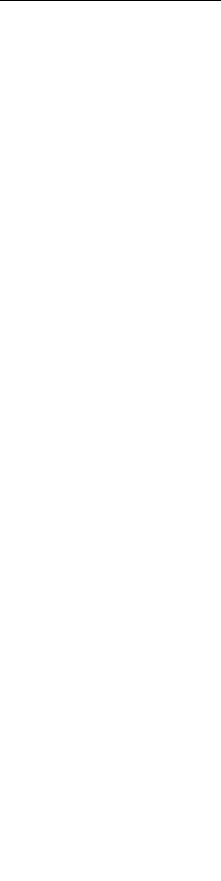 & $\begin{array}{l}\text { 12) } \\
\text { 13) } \\
\text { 14) } \\
\text { 15) } \\
\text { 16) } \\
\text { 18) }\end{array}$ & $\begin{array}{l}\text { milik KWLM. } \\
\text { Melakukan pemasaran dan } \\
\text { penjualan kayu. } \\
\text { Mengirimkan kayu dari depo } \\
\text { kayu sampai ke industri atau } \\
\text { buyer. } \\
\text { Menyiapkan kelengkapan } \\
\text { dokumen administrasi } \\
\text { penjualan dan legalitas kayu. } \\
\text { Melunasi sisa pembayaran } \\
\text { kayu kepada petani. } \\
\text { Memberikan bantuan } 10 \text { bibit } \\
\text { pohon kepada petani setiap } \\
\text { menebang } 1 \text { pohon. } \\
\text { Melakukan pembinaan } \\
\text { kepada petani hutan rakyat. } \\
\text { Mengelola dan membiayai } \\
\text { sertifikasi FSC. }\end{array}$ & & \\
\hline 3. & Regu tebang & Tida & ak ada & $\begin{array}{l}\text { 1) } \\
\text { 2) } \\
\text { 3) }\end{array}$ & $\begin{array}{l}\text { Melakukan penebangan pohon di } \\
\text { lahan. } \\
\text { Melakukan penyaradan kayu } \\
\text { dari lahan sampai di tepi jalan } \\
\text { angkutan. } \\
\text { Mengangkut log dari tepi jalan } \\
\text { angkutan ke Tempat } \\
\text { Penimbunan Kayu Terdaftar } \\
\text { (TPT). }\end{array}$ \\
\hline 4. & PT. SOBI & Tida & ak ada & $\begin{array}{l}\text { 1) } \\
\text { 2) } \\
\text { 3) } \\
\text { 4) } \\
\text { 5) } \\
\text { 6) } \\
\text { 7) }\end{array}$ & $\begin{array}{l}\text { Melakukan pemetaan lahan } \\
\text { hutan rakyat. } \\
\text { Melakukan inventarisasi potensi } \\
\text { tegakan hutan rakyat. } \\
\text { Menyusun rencana pengaturan } \\
\text { kelestarian pemanenan kayu. } \\
\text { Melakukan pembelian kayu dari } \\
\text { petani. } \\
\text { Melakukan pembayaran uang } \\
\text { muka (DP) kepada petani } \\
\text { sebesar } 60 \% \text { dari harga kayu. } \\
\text { Melakukan pemasaran dan } \\
\text { penjualan kayu. } \\
\text { Mengirimkan kayu dari depo } \\
\text { kayu (TPT) sampai ke industri } \\
\text { atau buyer. } \\
\text { Melunasi sisa pembayaran kayu } \\
\text { kepada petani. } \\
\text { Mengelola dan membiayai } \\
\text { sertifikasi FSC. }\end{array}$ \\
\hline
\end{tabular}




\begin{tabular}{|c|c|c|c|c|c|}
\hline 5. & $\begin{array}{l}\text { Industri } \\
\text { pengolah kayu }\end{array}$ & $\begin{array}{l}\text { 3) } \\
\text { 4) } \\
\text { 5) }\end{array}$ & $\begin{array}{l}\text { Membeli kayu sertifikasi dari } \\
\text { KWLM. } \\
\text { Melakukan pembayaran uang } \\
\text { muka pembelian kayu kepada } \\
\text { KWLM sebesar } 60 \% \text { dari } \\
\text { harga kayu. } \\
\text { Melunasi sisa pembayaran } \\
\text { kayu kepada KWLM setelah } \\
\text { kayu diterima. } \\
\text { Mengolah kayu menjadi } \\
\text { produk olahan kayu } \\
\text { Menjual produk olahan kayu } \\
\text { bersertifikasi kepada } \\
\text { konsumen }\end{array}$ & $\begin{array}{l}\text { 1) } \\
\text { 2) } \\
\text { 3) } \\
\text { 4) }\end{array}$ & $\begin{array}{l}\text { Membeli kayu sertifikasi dari PT } \\
\text { SOBI. } \\
\text { Melakukan pembayaran uang } \\
\text { muka pembelian kayu kepada } \\
\text { PT SOBI sebesar } 60 \% \text { dari harga } \\
\text { kayu. } \\
\text { Melunasi sisa pembayaran kayu } \\
\text { kepada PT SOBI setelah kayu } \\
\text { diterima. } \\
\text { Mengolah kayu menjadi produk } \\
\text { olahan kayu } \\
\text { Menjual produk olahan kayu } \\
\text { bersertifikasi kepada }\end{array}$ \\
\hline
\end{tabular}

Sumber: Data primer.

\section{Kendala pemasaran kayu sertifikasi}

Manfaat yang diperoleh oleh para petani hutan rakyat setelah menjadi anggota KWLM dan memperoleh sertifikasi FSC adalah sebagai berikut: (1) Penentuan harga kayu lebih transparan; (2) Mendapatkan harga kayu lebih tinggi dibandingkan harga kayu non sertifikasi; (3) Dapat mengajukan kredit atau pinjaman uang dengan jaminan pohon; (4) Mendapatkan bantuan bibit pohon gratis setelah melakukan penebangan; (5) Mendapatkan pembinaan tentang pengelolaan hutan lestari; (6) Mendapatkan deviden atau sisa hasil usaha (SHU).

Namun demikian, masih ada beberapa kendala yang dihadapi oleh para petani hutan rakyat dalam pemasaran kayu sertifikasi, yaitu: (1) Pembayaran kayu tidak dilakukan secara cash (kontan) seperti yang dilakukan oleh bakul atau pengepul kayu non-sertifikasi; (2) Persyaratan administrasi penjualan dan legalitas kayu sertifikasi lebih rumit dibandingkan kayu non-sertifikasi; (3) Perhitungan harga kayu tidak dilakukan dalam bentuk kayu log yang sudah berada di tepi jalan angkutan sehingga petani harus menanggung biaya penebangan dan penyaradan. Diantara ketiga kendala tersebut kendala yang paling utama menurut petani adalah pembayaran yang tidak dilakukan secara kontan (cash). Padahal alasan petani menjual kayu adalah untuk mendapatkan uang dalam jumlah besar dan dalam waktu mendesak. Kondisi ini menyebabkan banyak petani hutan rakyat sertifikasi yang masih menjual kayu kepada para bakul atau pengepul, meskipun kayu tersebut dihargai sama dengan kayu nonsertifikasi. Meskipun kayu yang dibeli berasal dari hutan rakyat sertifikasi FSC, tetapi para bakul atau pengepul tersebut tidak dapat mengklaim sebagai kayu sertifikasi karena mereka tidak memiliki sertifikat FSC.

Sementara itu, terkait kendala administrasi penjulan dan legalitas kayu sebenarnya sudah tidak menjadi masalah karena tanggung jawab untuk melengkapinya dilakukan oleh KWLM, bukan oleh petani. Petani hanya diminta untuk menyedikan salinan KTP dan bukti kepemilikan lahan. Demikian halnya dengan kendala petani untuk menanggung biaya penebangan dan penyaradan kayu sebenarnya juga sudah tidak menjadi masalah karena biaya tersebut dibayarkan (ditalangi) oleh KWLM, tidak dibayarkan langsung oleh petani. KWLM akan membayar harga kayu (log) kepada petani setelah dikurangi dengan biaya penebangan dan penyaradan tersebut.

\section{KESIMPULAN}

Hasil penelitian menunjukkan bahwa: (1) pola rantai pemasaran kayu sertifikasi lebih sederhana dibandingkan dengan pemasaran kayu non sertifikasi; (2) aktor-aktor yang terlibat dalam rantai pemasaran kayu sertifikasi adalah petani pemilik kayu, regu tebang, koperasi, PT. SOBI, industri pengolahan kayu; (3) kendala utama yang dihadapi oleh petani dalam pemasaran kayu sertifikasi 
adalah pembayaran yang tidak dilakukan secara cash seperti yang dilakukan oleh para pedagang kayu non-sertifikasi.

\section{UCAPAN TERIMA KASIH}

Kami mengucapkan terima kasih dan penghargaan kepada parapihak yang telah membantu dan mendukung terlaksananya penelitian ini, antara lain yaitu: (1) Para pengurus dan anggota KWLM yang telah berkenan memberikan data dan informasi berharga yang kami butuhkan selama melakukan penelitian; (2) Para mahasiswi kami yaitu Eny dan Okta yang telah banyak membantu dalam pengambilan data di lapangan; (3) Sekolah Vokasi Universitas Gadjah Mada yang telah membiayai penelitian ini.

\section{DAFTAR PUSTAKA}

Awang, San Afri, Heri Santoso, Wahyu Tri Widayanti, Yuli Nugroho, Kustomo, Sapardiono. (2001). Gurat Hutan Rakyat Di Kapur Selatan, DEBUT Press, Yogyakarta.

Badan Pusat Statistik Kabupaten Kulon Progo. (2012). Kabupaten Kulon Progo Dalam Angka 2011. Kulon progo: BPS Kabupaten Kulon Progo.

Dinas Pertanian dan Kehutanan Kabupaten Kulon Progo. (2015). Data Perkembangan Luas Hutan Rakyat di Kabupaten Kulon Progo.

Harada, Kazuhiro, Rohman, Silvi Nur Oktalina, Wiyono. (2012). Exploring Potentials of Forest Certification for Community-based Forest Management in Indonesia. Journal of Forest Economics. Vol.58 No.1 (2012), Japan. Page 58 - 67.

Harada, Kazuhiro, Wiyono. (2014). Certification of a Community-based Forest Enterprise for Improving Institutional Management and Household Income: A Case from Southeast Sulawesi, Indonesia. Journal of Small-scale Forestry. March 2014, Volume 13, Issue 1, page 47-64. DOI 10.1007/s11842-013-9240-8. Published online on Springer. Link: http://link.springer.com/article/10.1007/s11842-013-9240-8

Hinrich, A, Muhtaman, D.R, dan Irianto, N. (2008). Sertifikasi Hutan Rakyat Di Indonesia. GTZ. Jakarta.

Koperasi Wana Lestari Menoreh. (2010). Rencana Pengelolaan Hutan Rakyat Koperasi Wana Lestari Menoreh (KWLM), Kabupaten Kulon Progo, DIY.

(2012). Laporan Pengelolaan Hutan Rakyat Koperasi Wana Lestari Menoreh (KWLM), Kabupaten Kulon Progo, DIY.

Maryudi, A. (2005a). Strategi Pengelolaan Hutan Rakyat Lestari. Prosiding Seminar Nasional Pengembangan Pengelolaan dan Pemanfaatan Hasil Hutan Rakyat. 12 Desember 2005. Yogyakarta, Halaman 98 - 104.

. (2005b). Beberapa Kendala bagi Sertifikasi Hutan Rakyat. Jurnal Hutan Rakyat: 7(3): 25 29. Pusat Kajian Hutan Rakyat. Yogyakarta.

(2006). Sertifikasi Hutan: Instrumen Baru dalam Kebijkan Kehutanan. Rimba Kalimantan: Vol 11 No.1, Halaman 27 - 35.

Pemerintah Kabupaten Kulon Progo. (2015). http://www.kulonprogokab.go.id/v21/KondisiUmum_6_hal. Diakses pada tanggal 30 Juli 2015.

Wiyono dan Silvi Nuroktalina. (2013). Analisis Kelembagaan Pada Program Sertifikasi Hutan Rakyat di Kabupaten Gunungkidul. Prosiding Seminar Nasional Teknologi Terapan: Pengembangan Teknologi Terapan yang Unggul, Bermartabat dan Profesional. Sekolah Vokasi, Universitas Gadjah Mada, Yogyakarta. Volume 1B, No.1, Oktober 2013, Halaman 1 - 8. 